\title{
Strategies for Developing Cross-cultural Communication Competence in College English Based on Small Private Online Course (SPOC)
}

\author{
Zhou Tang \\ Tianjin University of Finance and Economics Pearl River College, Tianjin 301111, China \\ Email:649434098@qq.com
}

Abstract: Under the background of blended teaching, the approaches to enhance college students' ability to use English in multi-cultural environment are being diversified. This paper explains the importance of cross-cultural communication competence, discusses the features of SPOC and explores the strategies of applying SPOC to the development of cross-cultural communication competence in college English classes.

Keywords: cross-cultural communication, SPOC, college English

\section{Introduction}

In China, cultivating cross-cultural talents has become an important mission of higher education, and foreign language education is the main channel for cultivating cross-cultural communication skills. In recent years, the necessity of improving intercultural communication skills has been repeatedly mentioned in College English Curriculum Requirements (2007). Therefore, cultivating high-quality talents with intercultural communication skills has become one of the important goals of college English teaching. The latest College English Curriculum Requirements formulated by the Ministry of Education clearly states that the goal of college English teaching is to cultivate students' English application ability, enhance crosscultural communication awareness and communication skills, and at the same time develop independent learning ability, improving comprehensive cultural literacy and enabling them to effectively use English in their study, living, socializing and work in the future in order to meet the needs of the country, society, school and personal development. By consulting literature databases such as CNKI, it can be found that domestic scholars have done a lot of preliminary research. Gao Yongchen (2016) conducted a wide range of sample surveys on the cross-cultural communicative competence of domestic college students, and analyzed the influence of variables such as gender, college entrance examination scores, grade, and major on the acquisition of cross-cultural competence. Ge Chunping and Wang Shouren (2016) interpreted the meaning of cross-cultural communicative competence and proposed the specific content of college English cross-cultural communicative teaching. However, due to the compression of college English courses, the orientation of grade examinations, the limitations of teaching environment and methods, etc., the amount of information input, the flexibility of learning, and the role of students as the main body have been greatly restricted. These limitations in college English classes are mainly reflected in the following aspects. (1) The content of the teaching materials is outdated and cannot be updated in time. (2) Classroom organization is monotonous and students have insufficient experience. (3) The cultural input is single, and the content and means are insufficient. With the advent of the Internet information age, the use of information technology and multimedia teaching resources to build a "online + offline" blended teaching model is a new way for non-English majors to cultivate cross-cultural competence.

\section{Features of blended teaching and SPOC}

Blended teaching refers to the combination of online teaching and traditional face-to-face teaching, giving play to their respective advantages, highlighting the leading role of teachers and the initiative of students, and shifting from "teacher-centered" to "student-centered" (Westerklaken , 2019). Through multi-form teaching design and refined teaching management, it intends to stimulate students' learning motivation and cultivate their independent learning ability, so as to obtain more in-depth teaching effects (He Kekang, 2004). The 2019 Horizon Report (Higher Education Edition) predicts that blended learning will be the main development trend of world higher education in recent years. Research has found that blended teaching can not only make full use of high-quality online teaching resources, but also improve student learning effectiveness and satisfaction (Dziuban et al., 2011; Dziuban et al., 2011; Means et al., 2013), as well as group cooperation Consciousness (Rovai et al., 2004). Among them, SPOC (Small Private Online Course) is one of the most representative courses. SPOC is a small-scale open online course developed on the basis of MOOC (Massive Open Online Courses). It 
refers to both the course and the online learning platform on which the course is based. SPOC is an emerging concept that mainly addresses the problems of low attendance rate, weak pertinence, and low degree of personalization of MOOCs. Different from MOOC's large-scale pure network teaching mode, SPOC is smaller in scale and more flexible, controllable and maneuverable. SPOC can apply high-quality resources to small-scale online classroom with access restrictions. For example, teaching resources such as videos, courseware, online homework and tests in MOOC can be applied to online courses of small-scale student groups. Students of different levels choose learning materials of different levels of difficulty for learning and discussion, and teachers provide online guidance and answer questions. This effectively makes up for the lack of interaction and of teaching students in accordance with their aptitude in MOOC mode. It can be said that SPOC combines the advantages of large-scale online open courses and of small-class traditional classroom teaching, realizing the integration of online learning and traditional learning. It not only improves the completion rate of online open courses and students' self-learning ability, but also improves the quality of teaching and learning in college. However, there are not many domestic studies on blended teaching, especially on SPOC in promoting the cultivation of college English cross-cultural communicative competence. Based on the above considerations, a discussion will be conducted on the strategies of applying SPOC to the development of cross-cultural communication competence in college English classes.

\section{Strategies of applying SPOC to the development of cross-cultural communication competence in college english classes}

Based on the above analysis of the advantages of SPOC, it can be seen that SPOC integrates the advantages of MOOC, makes up for the shortcomings of traditional classroom teaching, achieves complementary advantages, enriches teaching models and improves teaching effectiveness. A detailed discussion will be held from three perspectives.

\subsection{Pre-class preparation}

In the pre-class preparation stage, the instructor can make full use of unlimited network resources, collect a large number of cross-cultural teaching materials, make various types of learning materials, such as videos, audios, text materials, etc., and upload them to the Internet. This makes the students' cross-cultural experience and learning channels more abundant, so that students can come into contact with the authentic cross-cultural language environment outside the traditional classroom. At this stage, teachers can make flexible adjustments to SPOC courses based on offline teaching content. For example, in units with more theoretical content, they can produce more vivid examples or online learning materials with practical content; for those who lack background introduction, corresponding background knowledge can be supplemented in them, so that students can get in touch with relevant history and culture in advance. In addition, due to the small number of students in the SPOC course (generally only limited to the teacher's own students), teachers can classify students through entrance exams, previous course scores, past performance, personality, strengths and weaknesses, questionnaires, etc., and then make courseware of different difficulty and quantity for different types of students, and set different learning progress. For example, students who are more familiar with the background and cultural knowledge of the corresponding unit may be required to learn more difficult and profound contents, and vice versa.

\subsection{Teaching process}

In blended teaching, the teaching process is divided into two stages, online and offline. Online learning should make full use of some of the outstanding advantages of SPOC. First of all, due to the small number of SPOC students, attendance is better managed. Although excellent teachers do not need to worry about attendance, it cannot be denied that SPOC can explicitly or implicitly create pressure on students to attend, which is beneficial to some relatively lazy students. Second, SPOC courses have fewer restrictions on the time and location of lectures, especially with the rapid development and popularization of mobile devices now, so that students can make full use of "fragmented" time for learning. This "fragmented" learning model is especially suitable for students who usually have more courses and less spare time; in addition, due to the repeatability of online learning materials, if students do not understand for the first time, or do not understand some parts of the offline courses, they can also learn online after class, replaying and thinking about difficult knowledge points many times until they understand and digest them. Third, due to the small number of classes, SPOC's teacher-student interaction and student-student interaction are more effective than MOOC. Teachers are more controllable about the courses, and they can also keep abreast of students' learning progress and status in a timely manner. In addition, SPOC courses generally have a discussion board. Teachers can use this board to encourage students to discuss, realizing teacher-student and student-student interaction. In addition, students can also develop their cross-cultural thinking and communication skills in English through methods such as posting replies, giving likes, and AI interaction. These are to give students a stage to show themselves and help students improve their self-confidence. 
Since students have learned part of the relevant content in the SPOC, teachers can be more deliberate in the allocation of offline course time, which means that more time can be used for activities related to cross-cultural competence training. In addition to theoretical knowledge, cross-cultural competence training pays more attention to students' practice and experience under the guidance of teachers, which is the advantage of offline courses. First of all, we must pay attention to the coordination between offline cross-cultural training and the content of the previous online SPOC course. Online content must not only be understood as a supplement to offline courses, but should also be the subject of offline cross-cultural communication practice activities. Teachers can combine online materials to expand topics in offline classrooms, so that students can understand the application of cross-cultural theories, which they have learned, in practical fields. In this way, they learn to analyze cultural differences in life, and improve their practical ability in cross-cultural communication, which allows students to further understand and consolidate their knowledge of online learning. Second, pay attention to creating a cross-cultural communication atmosphere through interaction, which is also the biggest advantage of traditional classrooms. For example, for the theme of a certain unit, teachers provide relevant cross-cultural interaction cases in online learning materials to stimulate students to think from multiple perspectives, and then conduct group discussions in offline classrooms; or the teachers can set up scene simulation exercises, such as role playing, sitcoms and other teamwork tasks in order to enhance students' sense of experience and reality, and improve their ability to use communicative strategies. In addition, in a face-to-face situation, students and teachers can interact with each other on certain issues. Teachers can use language, movements and other vivid ways to describe and analyze the issue, inspiring and inducing students to increase their interest in learning. At the same time, it also excellently cultivated students' ability to analyze and solve problems. Third, teachers can more directly receive feedbacks about the learning status and acceptance of students in offline classrooms, and decide whether to adjust the content, difficulty, and progress of subsequent online courses, so that students can truly master the content and meet the requirements.

In the course of teaching, there are several points that need to be noted. (1) Whether online or offline, students' language ability, communication ability and skill training should run through the entire teaching process. (2) Some content that is not taught in offline classes must be published in SPOC in advance. In the announcement, it is necessary to write clearly what content requires students to complete by self-study before class, so as to achieve the continuity. If students do not fully prepare before offline class, it is impossible to achieve the expected teaching effect. (3) For the content that is not required or expanded in the syllabus, teachers can point out in the SPOC, and students who are capable or interested can choose to study, so that teachers can try their best to cater for students with different foundations and abilities. In this way, each type of student can, while completing basic learning tasks, take what they need respectively to achieve higher goals and improve their performance.

\subsection{Homework and evaluation system}

In addition to traditional offline homework, teachers can also use SPOC as an important homework and test platform. They can publish homework based on the content of each offline class, and can also regularly release various types of homework or tests with different content for students of different abilities, so as to check students' acquisition in an all-round way and help them continue to improve. Homework can be submitted multiple times to get the highest score, allowing students to strengthen their knowledge through continuous repetition. In addition, teachers can use SPOC data analysis to summarize the students' learning status. For example, the frequency of watching a certain video is high, indicating that students are more interested in the topic in this video, which can be emphasized in the offline classroom; the higher error rate in a certain exercise indicates that the student does not have a good grasp of a certain knowledge; the data from the homework can be used to analyze whether the student has kept up with the progress, and the students who have not kept up with the progress can be supervised in time; based on the results of data analysis, teachers can even contact some students with learning difficulties to understand the reasons and help develop differentiated learning strategies. At the same time, the final grade is no longer primarily based on traditional summative evaluation. You can use SPOC's online comments, learning logs, peer review and other functions to make more humanized and diversified evaluations. This continuous process evaluation interacts with the learning process, which has a guiding effect on learning (Jiang Yanhua 2007), and encourages students to actively reflect on and summarize the learning process.

\section{Summary}

With the blended teaching model based on SPOC, students' learning methods and approaches have been expanded, and their enthusiasm has been aroused. The atmosphere in classroom is more active, and students' cross-cultural communication knowledge can be increased. At the same time, this model also redefines the role of teachers. The use of SPOC for blended teaching is a new challenge for many teachers. Teachers need to be proficient in computer and network technology. They 
also need to expand their cultural knowledge to enrich the content of a lesson being prepared, which promotes teachers to improve their professional proficiency faster. Therefore, under the current background of calling for the reduction of college English class hours while emphasizing the cultivation of college students' global vision, it is a good strategy to use this model for cross-cultural teaching.

\section{References}

[1] Dziuban,C.\& P. Moskal. A Course is a Course is a Course: Factor Invariance in Student Evaluation of Online,Blended and Face-to-face Learning Environments. Internet and Higher Education, 2011,4, 236-241.

[2] Dziuban,C., Graham,C.R. Moskal,P.D. Norberg,A.\&N.Sicilia. Blended Learning: The New Normal and Emerging Technologies. International Journal of Educational Technology in Higher Education, 2018, 1, 1-16.

[3] Gao Yongchen. A Survey on the Intercultural Communication Competence of Chinese College Students. Foreign Languages and Their Teaching, 2016, 3, 71-78.

[4] Ge Chunping and Wang Shouren. On Cultivation of Intercultural Communicative Competence in College English Teaching. Foreign Languages and Their Teaching, 2016, 2, 79-86.

[5] He Kekang. The New Development of Educational Technology Theory from Blending Learning. E-education Research, 2004, 3, 1-6.

[6] Jiang Yanhua. On the Identity of Process Evaluation and Result Evaluation. Forum on Contemporary Education, 2007,4,52-53.

[7] Means,B.,Toyama,Y.,Murphy,R.\& M. Baki. The Effectiveness of Online and Blended Learning: A Meta-analysis of the Empirical Literature. Teachers College Record, 2013,3,1-47.

[8] Norberg,A.,C. Dziuban \& P. Moskal. A Time Based Blended Learning Model. On the Horizon, 2011,3,207-216.

[9] Rovai,A. \& H. Jordan. Blended Learning and Sense of Community: A Comparative Analysis with Traditional and Fully Online Graduate Courses. International Review of Research in Open and Distance Learning, 2004.5.

[10] Westerlaken. M, Christiaans Dingelhoff. I, Renee M, et al. Blended Learning for Postgraduates: An Interactive Experience. BMC Medical Education, 2019, 19, 289. 